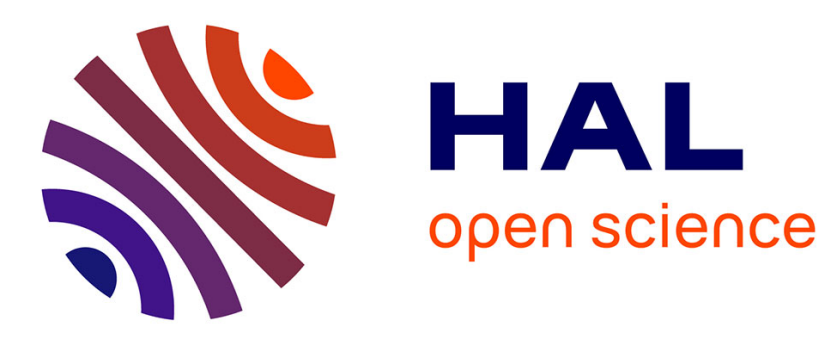

\title{
A simple inverse procedure to determine heat flux on the tool in orthogonal cutting
}

Julien Yvonnet, Domenico Umbrello, Francisco Chinesta, Fabrizio Micari

\section{To cite this version:}

Julien Yvonnet, Domenico Umbrello, Francisco Chinesta, Fabrizio Micari. A simple inverse procedure to determine heat flux on the tool in orthogonal cutting. International Journal of Machine Tools and Manufacture, 2006, 46 (7-8), pp.820 - 827. 10.1016/j.ijmachtools.2005.07.030 . hal-01004943

\section{HAL Id: hal-01004943 https://hal.science/hal-01004943}

Submitted on 2 Apr 2017

HAL is a multi-disciplinary open access archive for the deposit and dissemination of scientific research documents, whether they are published or not. The documents may come from teaching and research institutions in France or abroad, or from public or private research centers.
L'archive ouverte pluridisciplinaire HAL, est destinée au dépôt et à la diffusion de documents scientifiques de niveau recherche, publiés ou non, émanant des établissements d'enseignement et de recherche français ou étrangers, des laboratoires publics ou privés. 


\title{
A simple inverse procedure to determine heat flux on the tool in orthogonal cutting
}

\author{
J. Yvonnet ${ }^{\mathrm{a}}$, D. Umbrello ${ }^{\mathrm{b}}$, F. Chinesta ${ }^{\mathrm{a}}$, F. Micari $^{\mathrm{c}}$ \\ a IMSP UMR 8106 CNRS, ENSAM-ESEM, Paris, France \\ ${ }^{\mathrm{b}}$ Department of Mechanical Engineering, University of Calabria, Cubo 45C, Arcavacata di Rende, 87036 Rende, Italy \\ ${ }^{\mathrm{c}}$ Department of Mechanical Technology, Production and Management Engineering, University of Palermo, Palermo, Italy
}

\begin{abstract}
The applications of numerical simulation to machining processes have been more and more increasing in the last decade: today, a quite effective predictive capability has been reached, at least as far as global cutting variables (for instance cutting forces) are concerned. On the other hand, the capability to predict local cutting variables (i.e. stresses acting on the tool, temperature distribution, residual stresses in the machined surface) has to be furtherly improved, as well as effective experimental procedures to validate numerical results have to be developed.

The aim of this paper is the proposition of an innovative approach, based on an simple inverse procedure, in order to identify both the heat flux flowing into the tool through the rake face and the heat transfer coefficient between the tool and the environment during a typical orthogonal cutting process. It is worth pointing out that the effective determination of such quantities is necessary in order to carry out a reliable prediction of the temperature distribution in the tool during the process.

The procedure is based on the integration of numerical simulations, inverse approach algorithms and experimental tests.
\end{abstract}

Keywords: Heat flux; Split-tool; FEM; Inverse approach

\section{Introduction}

In the last two decades, finite element techniques have achieved a very satisfactory level of development and reliability; in particular, the capability of the utilized codes to model cutting processes has supplied new powerful tools for machining processes analysis, although orthogonal cutting has been mainly taken into account, due the well known geometrical simplifications.

Nowadays, a relevant know-how about some relevant simulation issues can be considered as fully assessed: several topics, such as material behaviour under high strain, strain rate and temperature conditions, friction on the rake face of the tool and chip generation and development have been investigated by several researchers all over the world [1-9]. As well as a satisfactory prediction of global variables, for instance the cutting forces, is nowadays possible, even utilizing simple simulation tools.

On the other hand, several other issues related to machining processes require a deeper research effort, many of which are strictly related to the industrial application of machined parts: problems such as residual stresses prediction and control on the machined surfaces, simulation of complex fully 3D operations or, finally, cutting temperatures and tool wear prediction during machining operations are just few examples of new emerging needs.

During machining processes cutting tools are subjected to mechanical, thermal and tribo-chemical loads. In order to improve the scientific knowledge on machining technology and, moreover, in order to develop new powerful and reliable cutting tools, the simple knowledge of the global 


\begin{tabular}{|llll|}
\hline \multicolumn{2}{|l|}{ Nomenclature } & & \\
$a$ & tip-slot distance, $\mathrm{mm}$ & $R$ & residual vector in the Newton strategy \\
$A$ & thermocouple position & $t$ & time, $\mathrm{s}$ \\
$E$ & error & $T$ & temperature, ${ }^{\circ} \mathrm{C}$ or $\mathrm{K}$ \\
$C$ & heat capacity, $\mathrm{J} /\left(\mathrm{m}^{3} \mathrm{~K}\right)$ & $\mathrm{TOL}$ & numerical tolerance \\
$h$ & convection coefficient, $\mathrm{W} /\left(\mathrm{m}^{2} \mathrm{~K}\right)$ & $x$ & position, mm \\
$k$ & thermal conductivity $\mathrm{W} /(\mathrm{m} \mathrm{K})$ & $\varepsilon$ & sensibility parameter \\
$K$ & tangent matrix in the Newton strategy & $\lambda$ & heat flux-convection coefficient couple \\
$Q$ & heat flux, $\mathrm{J} /\left(\mathrm{m}^{2} \mathrm{~s}\right)$ & $\rho$ & mass density, $\mathrm{Kg} \mathrm{M}^{3}$ \\
\hline
\end{tabular}

mechanical and thermal loads acting on the tool is not sufficient. In turn, a sound prediction of pressure and heat flux distributions on the rake face is necessary, i.e. the analysis must be developed at a local level.

In the past, many attempts to determine the local distribution of normal and shear stresses on the tool surface were carried out using photoelastic materials for either the tool or the workpiece, cutting tool materials with a well defined limit of elasticity and tools characterized by a reduced contact length including split-tools [10-14].

More recently, some researchers proposed different approaches to quantify the stress distribution at the toolchip interface [15-17], mainly based on the use of split-tool dynamometers. Several experiments based on the same techniques were also performed by Buryta et al. [18] and by Tonshoff et al. [19].

Unfortunately, the use of experimental approaches, such as the split dynamometer, is very difficult and time consuming; on the other hand the development of a reliable numerical simulation, able to determine the stress distributions, would offer relevant advantages. A finite element analysis of the normal and the shear stresses distribution on the rake face in orthogonal cutting was proposed by McClain et al. [20]. Actually, the predicted normal stresses on the rake face only qualitatively agreed with the experimental distribution determined by other researchers.

Recently, a new approach, based on the integration of numerical and experimental techniques was proposed by Filice et al. [21]. They utilized a set of properly designed tools, characterized by proper cuts at well defined distances from the tool tip, to measure the pressure distribution in orthogonal cutting; as well they carried out extensive numerical simulations, achieving a satisfactory agreement between the experimental and the predicted results.

The basic idea of this paper is to apply the same philosophy of the previous paper (Filice et al. [21]), in order to identify the heat flux distribution flowing into the tool through the rake face by means of an inverse approach. The method here addressed is based in fact on the partitioning concept utilized by Filice et al. [21] to measure the pressure distribution on the tool in orthogonal cutting.

A set of different tools is utilized: each of them is characterized by a tight slot cut at a proper distance from the tool tip. In this way, the tool is partitioned into two regions fully independent from the thermal point of view: it means that, during machining, a portion of the total heat flux flows on each of the regions, determining in each of them a temperature distribution which only depends on the portion itself. More in detail, the temperature distribution in each region is not affected by the heat flux portion flowing into the other region of the tool.

In this way, some temperature values in the tool region closer to the tool tip are accurately measured by means of a thermocouple directly mounted on the tool flank. Then an inverse procedure is carried out to determine both the convection coefficient on the external surface of the cutting tool and the average heat flux flowing into the region of the tool closer to the tool tip. Repeating the same approach as above for each tool, i.e. at the varying of the distance of the tight slot from the tool tip, the whole heat flux distribution can be reconstructed.

In the following paragraphs of the paper, the subsequent steps of the research will be presented, namely the preliminary investigations to verify if the partitioning concept holds for thermal phenomena, the design of the utilized tools, the experimental tests and finally the inverse approach.

\section{Tool design}

As mentioned the inverse procedure is based on temperature data supplied by a thermocouple mounted on the flank face of the tool. Furthermore, the tight slot cut into the tool must ensure the effectiveness of the thermal partitioning described above. Therefore, a proper design of the instrumented tool is necessary.

Two constrains are involved in this design: (i) the thermal field in the former region of the tool, i.e. the one closer to the tool tip, must be independent on the heat flux flowing into the remaining portion of the chip-tool contact surface, at least for a cutting time $t_{\max }$ long enough for the application of the inverse procedure; (ii) the position of the thermocouple along the flank of the tool must permit to avoid local effects, i.e. an unique relationship should exist between the heat flux flowing into the former region of the tool and the temperature history measured by a thermocouple. 
Table 1

Thermal parameters

\begin{tabular}{llcl}
\hline & $\begin{array}{l}\text { Heat capacity } \\
\mathrm{J} /\left(\mathrm{m}^{3} \mathrm{~K}\right)\end{array}$ & $\begin{array}{l}\text { Thermal conduc- } \\
\text { tivity W/(m K) }\end{array}$ & $\begin{array}{l}\text { Mass density } \\
\left(\mathrm{Kg} / \mathrm{m}^{3}\right)\end{array}$ \\
\hline Tool & $3.79 \times 10^{6}$ & 50 & 7870 \\
Workpiece & $2.42 \times 10^{6}$ & 160 & 2700 \\
Calibrated plate & $2.83 \times 10^{6}$ & 0.09 & 2700 \\
\hline
\end{tabular}

A calibrated plate made of a material with a very low thermal conductivity was introduced in the slot. The material was Silica-Aluminous based ceramic fibres, characterized by service temperature up to $1260^{\circ} \mathrm{C}$, high stability, low thermal conductivity, low thermal storage capacity, excellent resistance to thermal shocks. The application of the calibrated plate was necessary both in order to ensure the thermal effects separation and to avoid chip introduction into the slot.

Table 1 reports the thermal parameters for the workpiece (Aluminum Alloy 6060-T5), the tool (HSS) and the calibrated plate (Silica-Alumina), as used in the FEM analysis.

In addition, the same authors have shown in a recent work [22], the validation of the proposed technique taking into account the cutting temperature distributions and the thermal separation effects by a comparison between the experimental evidences and the numerical results.

\subsection{Design of the optimum slot geometry}

A set of numerical simulations at the varying of the slot geometry was carried out in order to determine the above mentioned $t_{\max }$ value, i.e. the time length during which the thermal field in the former region of the tool, is independent on the heat flux flowing into the remaining portion of the chip-tool contact surface. The optimum tight slot design is reported in Fig. 1. It is characterized by a depth of $8 \mathrm{~mm}$ and an inclination angle of $45^{\circ}$.

Such design permits to obtain a cutting time $t_{\max }$ equal to $17 \mathrm{~s}$ as confirmed by the numerical results reported in

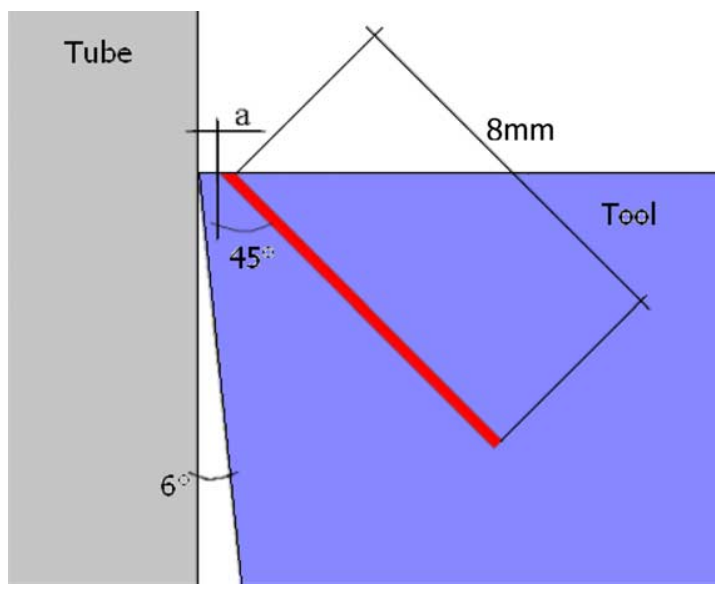

Fig. 1. The optimum slot design.
Figs. 2 and 3. Fig. 2 shows that applying a thermal flux only on the tool portion far away from the tool tip, after $17 \mathrm{~s}$ only the $10 \%$ of such flux flows into the former portion of the tool.

In turn, Fig. 3 shows that applying a thermal flux only in the portion of the tool closer to the tool closer to the tool tip, heat remains confined in such portion for more than $17 \mathrm{~s}$.

\subsection{Design of the optimum thermocouple position}

The thermal model is assumed isotropic and both the heat capacity and the thermal conductivity are assumed known. If, as mentioned, the cutting tool is characterized by a slot filled with an non-conductive material (whose conductivity $k_{\text {isol }}$ can be neglected, i.e. $k_{\text {isol }} \approx 0$ ), and the intensity of the convection effects on the tool surface are much smaller that the heat conduction mechanism, the following thermal result holds: it exists a position $x$ (see Fig. 4) that must be determined such that the temperature evolution at this position within the time interval $\left[0, t_{\max }\right]$ depends on the average heat flux

$\tilde{Q}=\frac{\int_{0}^{a} Q(y) \mathrm{d} y}{a}$

and in consequence it does not depend on the local details of $Q(y)$.

If the thermocouple is too near to the tool tip, the measured temperature evolution will depend on the local details of the incoming heat flux $Q(y)$ and not only on its average value $\tilde{Q}$. On the other hand, if the thermocouple is too far from the tool tip, the measured temperatures will not depend only on the average heat flux incoming in the former portion of the tool, but also they will be influenced by the heat flux flowing through the second portion of the tool.

According to the above reported reasons, it is possible to determine the best position $x$ within the $t_{\max }$ time interval minimizing the error $E(x)$ defined by

$E(x)=\frac{T(x, \tilde{Q})-T(x, Q(y))}{T(x, Q(y))}$

being $T(x, \tilde{Q})$ the temperature at position $x$ due to average heat flux $\tilde{Q}$ and $T(x, Q(y))$ the one due to the actual heat distribution.

For the sake of simplicity, the error minimization was carried out by assuming the heat flux distribution incoming on the former portion of the tool as reported in Fig. 5. If $Q_{\mathrm{a}}$ and $Q_{\mathrm{b}}$ are assumed equal to $1.5 \tilde{Q}$ and $0.5 \tilde{Q}$, respectively (their average value being $\tilde{Q}$ ), the validity of the results will be guaranteed for variations of the thermal fluxes with respect to the average heat flux lower than $50 \%$.

From the calculated error for different $x$ values within the $\left[0, t_{\max }\right]$ time interval we can conclude that for $x$ greater than $2 a$ the error is negligible. 


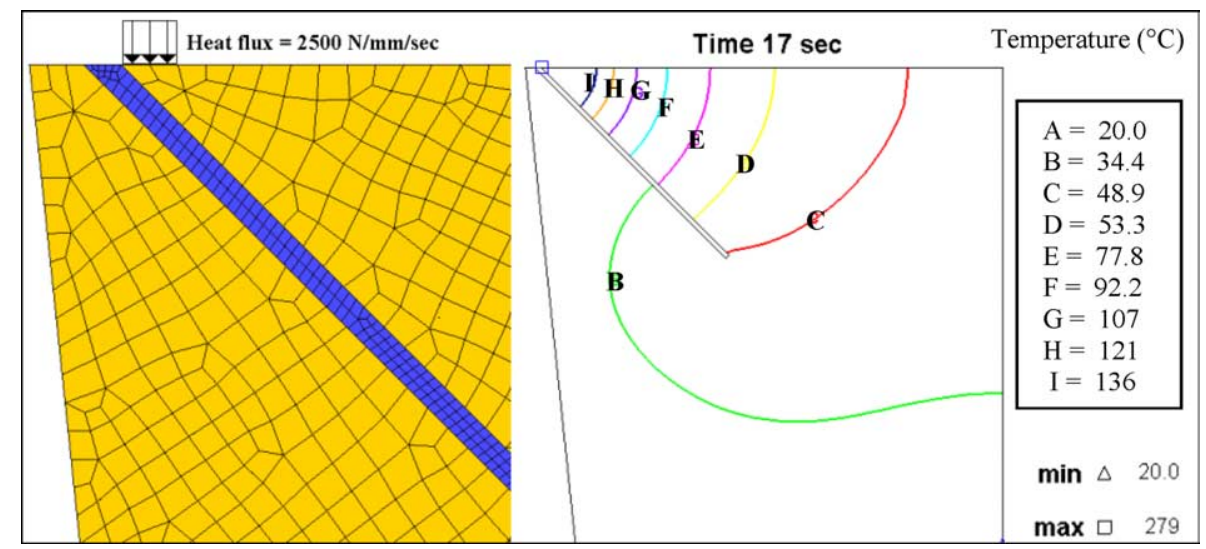

Fig. 2. After 17 s only the $10 \%$ of the applied heat flux flows into the former portion of the tool.

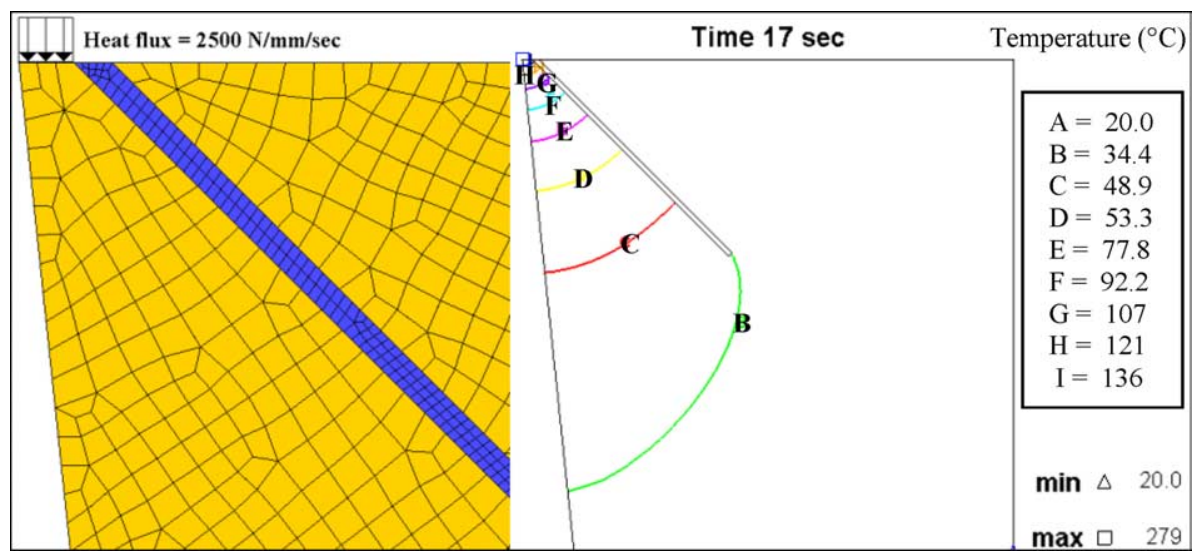

Fig. 3. Heat remains confined in the former portion of the tool for more than $17 \mathrm{~s}$.

According to these results and taking into account several constrains due to the dimensions of the thermocouple ( $1 \mathrm{~mm}$ diameter), the optimum distance from the tool tip was detected as equal to $2.25 \mathrm{~mm}$, as reported in Fig. 6 .

\section{Experimental tests}

The aim of the experimental tests was to measure the temperature profile related to each tool by using a Chromel ${ }^{\circledR} /$ Alumel ${ }^{\circledR}$ thermocouple (type K) mounted on the former portion of the tool (Fig. 7).

Four different tools were utilized (Fig. 8): three of them were manufactured by electrical discharge machine (EDM) cutting the tight slot with different distances between the tool tip and the slot, namely $0.35,0.5$ and $0.60 \mathrm{~mm}$; the last one was instrumented only with the thermocouple in order to measure the whole average heat flux flowing into the tool through the rake face.

The thermocouple with a diameter of $1 \mathrm{~mm}$ was embedded in the tool applying a force of about $50 \mathrm{~N}$ in order to ensure a sufficient adhesion [23]. Both the contact length and the thermocouple positions were measured utilizing a proper optical microscope. The former by depositing on the rake face a special paint and observing the rake face, the latter by observing a posteriori the tool section (along the hole axes) obtained by EDM.

The cutting speed and the feed rate was fixed to $125 \mathrm{~m} / \mathrm{min}$ and $0.4 \mathrm{~mm} / \mathrm{rev}$, respectively, to guarantee a tool-chip contact surface long enough to include all the slots (the measured contact length was about $2 \mathrm{~mm}$ ).

The experimental equipment was completed by a Personal Computer based on Intel Pentium IV technology

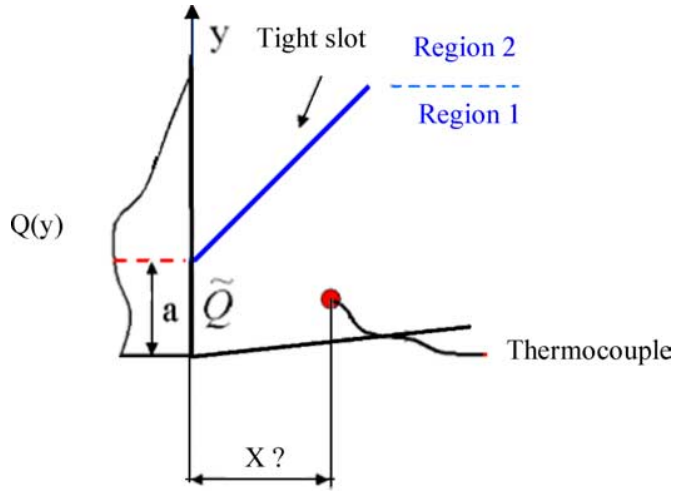

Fig. 4. Optimization of thermocouple position. 


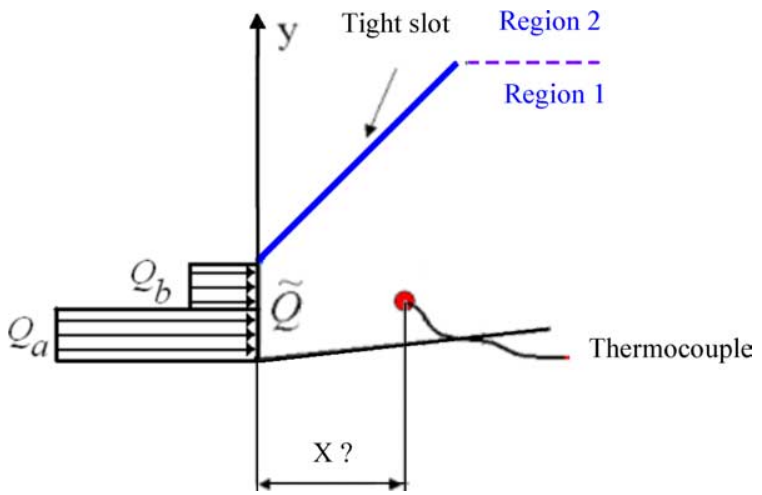

Fig. 5. Used model for error minimization.

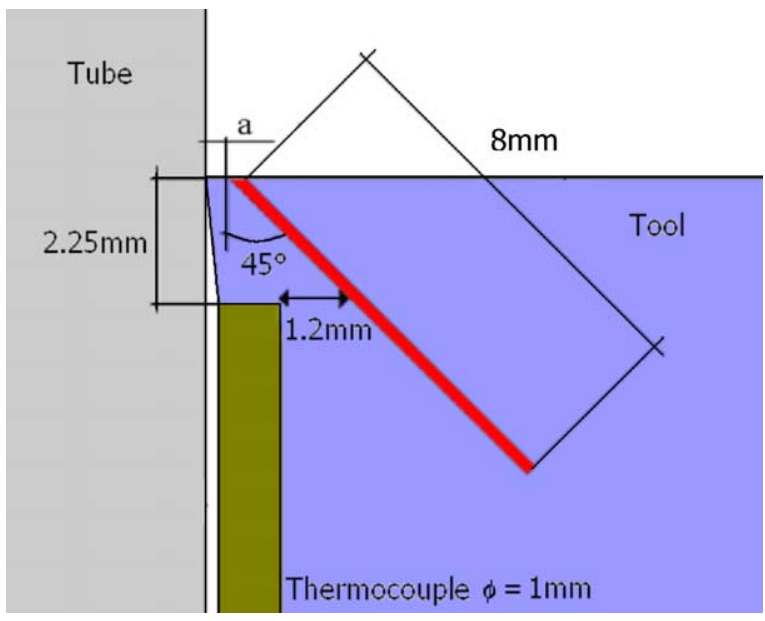

Fig. 6. Sketch of the tool utilized in the tests.

equipped with a data acquisition board (AT-MIO-16E-10 by National Instruments). The software used for the acquisition and the analysis of the data supplied by the thermocouple measuring devices was SG411 by Sint Technology.

Fig. 9 shows the average measured temperature histories during the experimental tests. All the tests were executed in the same environment conditions with almost three repetitions for each of them.

Depending on the slot position, i.e. depending on the position of the non-conductive plate, different fractions of the total heat flux flow into the former portion of the tool, determining different temperature curves; the more the non-conductive plane is far away from the tool tip, the higher is the heat amount flowing into the tool and the higher is the measured temperature. Of course the difference among the curves reduces after a certain cutting time that is when the partitioning effect disappears.

Fig. 9 also demonstrates that the partitioning effects is confirmed until $15 \mathrm{~s}$, while for a longer time the different tools reach the same temperature value of the tool without the slot, since the heat flux flowing into the second portion of the tool affects the whole tool.

\section{Heat flux identification using an inverse approach}

Using the divided tool technique described previously, the lower part of the tool was thermically isolated. The evolution of the temperature in time during cutting was measured at point A (see Fig. 10) using a thermocouple, which was positioned according to the discussion in Section 3 (Fig. 6).

For each tool, $i$ an average flux $\tilde{Q}_{i}$ on the isolated part of the rake face was determined through the inverse procedure described below, which in fact is associated with the real flux distribution $Q(y)$ on the considered part by the expression $\tilde{Q}_{i}=\int_{0}^{a_{i}} Q_{i}(y) \mathrm{d} y$.

Given different distances of the isolated band $a_{i}$ and the associated average fluxes $\tilde{Q}_{i}$, the real heat flux distribution $Q(y)$ can be approximated by a piecewise constant function (see Fig. 11) by means of the following scheme

$\tilde{Q}_{i}=Q_{1} ; \quad \tilde{Q}_{2}=\frac{Q_{1} a_{1}+Q_{2}\left(a_{2}-a_{1}\right)}{a_{2}} ;$

$\tilde{Q}_{i}=\frac{Q_{1} a_{1}+\sum_{j=2}^{i} Q_{j}\left(a_{j}-a_{j-1}\right)}{a_{i}}$

from which

$$
\begin{gathered}
Q_{1}=\tilde{Q}_{1} ; \quad Q_{2}=\frac{\tilde{Q}_{2} a_{2}-Q_{1} a_{1}}{a_{2}-a_{1}} ; \\
Q_{i}=\frac{\tilde{Q}_{i} a_{i}-Q_{1} a_{1}-\sum_{j=2}^{i-1} Q_{j}\left(a_{j}-a_{j-1}\right)}{a_{i}-a_{i-1}}
\end{gathered}
$$
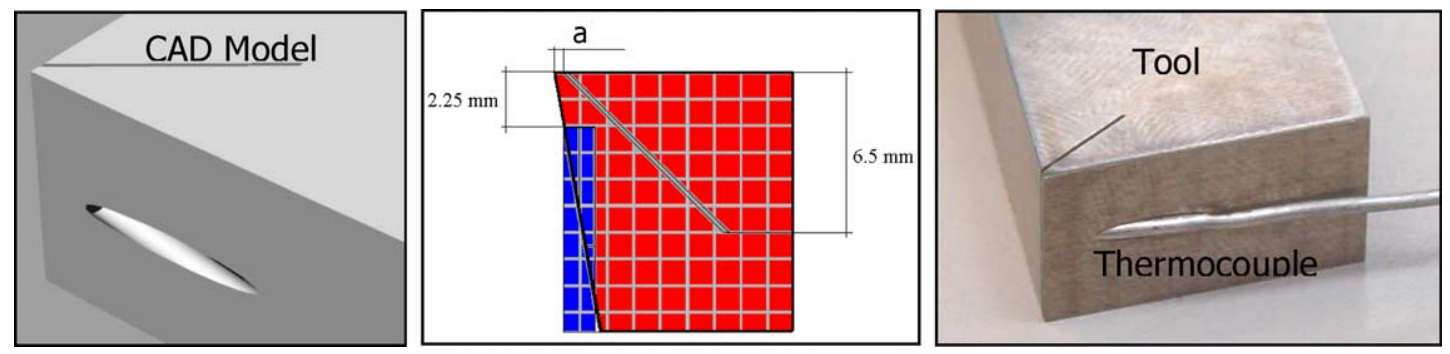

Fig. 7. The instrumented tool. 

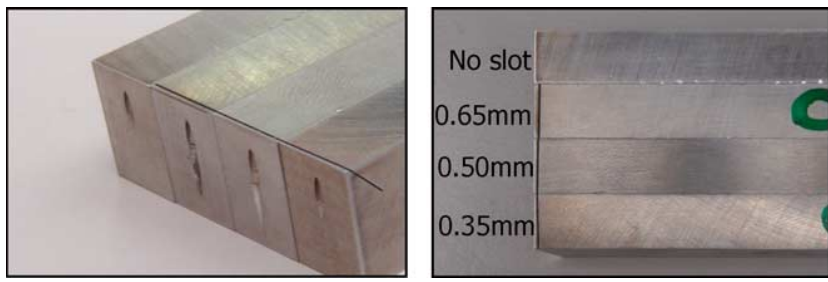

Fig. 8. The tools utilized in the experimental tests.

For a given $a_{i}$ value and the corresponding experimental temperature history $T_{\exp }(t)$ at point $A$, the average flux $\tilde{Q}_{i}$ was determined using the finite element model depicted in Fig. 12.

Identification of both unknowns, i.e. the average heat flux $\tilde{Q}_{i}$ and the convection coefficient $h$ (see Fig. 12) was possible by sing an iterative Newton-Raphson procedure to minimize the error defined by difference between the calculated and the experimental temperature history in point $A$ :

$E\left(\tilde{Q}_{i}, h\right)=\int_{0}^{t_{\max }}\left[T_{\text {num }}(A, t)-T_{\exp }(t)\right]^{2} \mathrm{~d} t$

The algorithm was the following:

Assume the initial values $\tilde{Q}_{\dot{j}}^{0}$ and $h^{0}$, or consider known their values at iteration $k$ : $\tilde{Q}_{i}^{k}$ and $h^{k}$

Compute the residual: $\mathbf{R}=\left\{\partial E^{k} / \partial \tilde{Q}_{i} ; \partial E^{k} / \partial h\right\}$. For this purpose, five temperature histories at position $A$ associated with the following conditions: $\left\{\tilde{Q}_{i}^{k} ; h^{k}\right\}$, $\left\{\tilde{Q}_{i}^{k}+\varepsilon_{Q} ; h^{k}\right\},\left\{\tilde{Q}_{i}^{k}-\varepsilon_{Q} ; h^{k}\right\},\left\{\tilde{Q}_{i}^{k} ; h^{k}+\varepsilon_{h}\right\}$ and $\left\{\tilde{Q}_{i}^{k} ; h^{k}-\right.$ $\varepsilon\}$ are calculated, thus permitting to compute the associated errors denoted by $E^{k}, E_{\varepsilon Q}^{k}, E_{-\varepsilon Q}^{k}, E_{\varepsilon h}^{k}$ and $E_{-\varepsilon h}^{k}$. The residual components are then defined by

$\frac{\partial E^{k}}{\partial \tilde{Q}_{i}}=\frac{E_{\varepsilon Q}^{k}-E_{-\varepsilon Q}^{k}}{2 \varepsilon_{Q}}$ and $\frac{\partial E^{k}}{\partial h}=\frac{E_{\varepsilon h}^{k}-E_{-\varepsilon h}^{k}}{2 \varepsilon_{h}}$

If $\|\mathbf{R}\|<$ TOL then $\left\{\tilde{Q}_{i}=\tilde{Q}_{i}^{k} ; h=h^{k}\right\}$; else continue

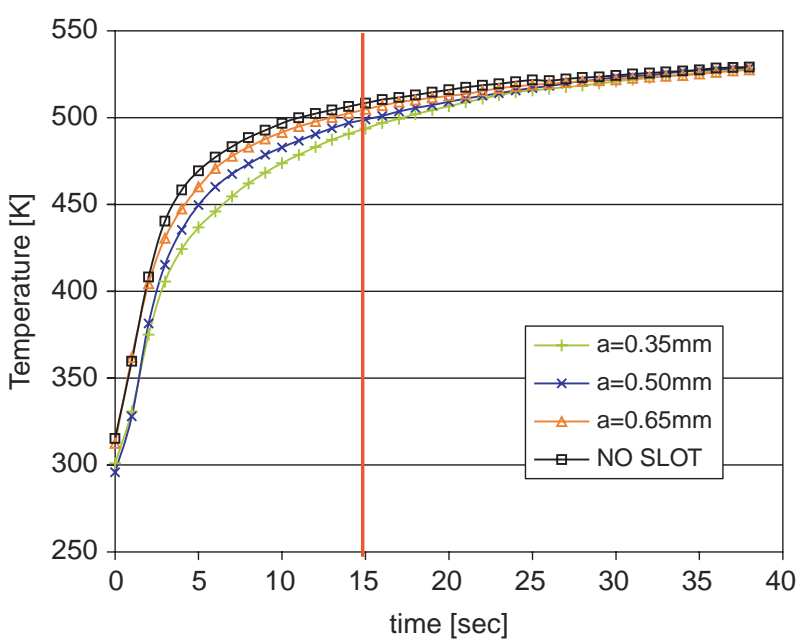

Fig. 9. Measured temperature histories.

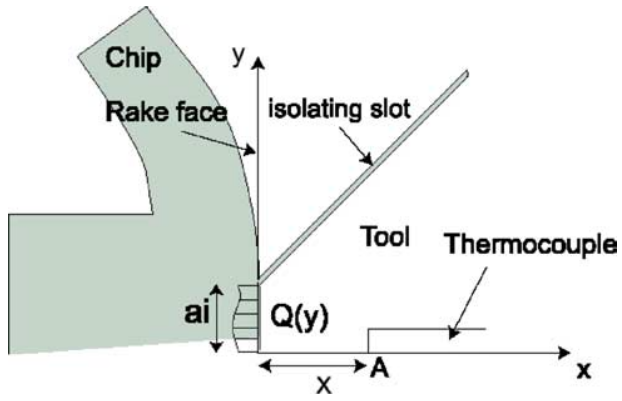

Fig. 10. Schematic view of the experimental setup.

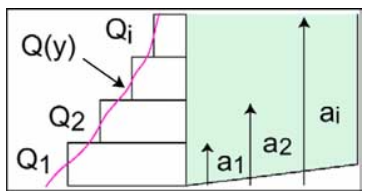

Fig. 11. Heat flux approximation.

Construct the tangent matrix. For this purpose compute four more temperature histories at position $A$ are calculated, namely, the ones associated to the following conditions: $\left\{\tilde{Q}_{i}^{k}+\varepsilon_{Q} ; h^{k}+\varepsilon_{h}\right\},\left\{\tilde{Q}_{i}^{k}-\varepsilon_{Q} ; h^{k}+\varepsilon_{h}\right\},\left\{\tilde{Q}_{i}^{k}+\right.$ $\left.\varepsilon_{Q} ; h^{k}-\varepsilon_{h}\right\}$ and $\left\{\widetilde{Q}_{i}^{k}-\varepsilon_{Q} ; h^{k}-\varepsilon_{h}\right\}$. They permit to compute the associated errors, denoted by $E_{\varepsilon Q, \varepsilon h}^{k}, E_{-\varepsilon Q, \varepsilon h}^{k}$ $E_{\varepsilon Q,-\varepsilon h}^{k}$ and $E_{-\varepsilon Q,-\varepsilon h}^{k}$, and therefore, the tangent matrix

$\mathbf{K}=\left(\begin{array}{cc}\frac{\partial^{2} E^{k}}{\partial \tilde{Q}_{i}^{2}} & \frac{\partial^{2} E^{k}}{\partial \tilde{Q}_{i} \partial h} \\ \frac{\partial^{2} E^{k}}{\partial \tilde{Q}_{i} \partial h} & \frac{\partial^{2} E^{k}}{\partial h^{2}}\end{array}\right)$

where the different components of the tangent matrix are the following

$\frac{\partial^{2} E^{k}}{\partial \tilde{Q}_{i}^{2}}=\frac{E_{\varepsilon Q}^{k}-2 E^{k}+E_{-\varepsilon Q}^{k}}{\varepsilon_{Q}^{2}}, \quad \frac{\partial^{2} E^{k}}{\partial h^{2}}=\frac{E_{\varepsilon h}^{k}-2 E^{k}+E_{-\varepsilon h}^{k}}{\varepsilon_{h}^{2}}$,

$\frac{\partial^{2} E^{k}}{\partial \tilde{Q}_{i} \partial h}=\frac{E_{\varepsilon Q, \varepsilon h}^{k}-E_{-\varepsilon Q, \varepsilon h}^{k}-E_{\varepsilon Q,-\varepsilon h}^{k}+E_{-\varepsilon Q,-\varepsilon h}^{k}}{4 \varepsilon_{Q} \varepsilon_{h}}$
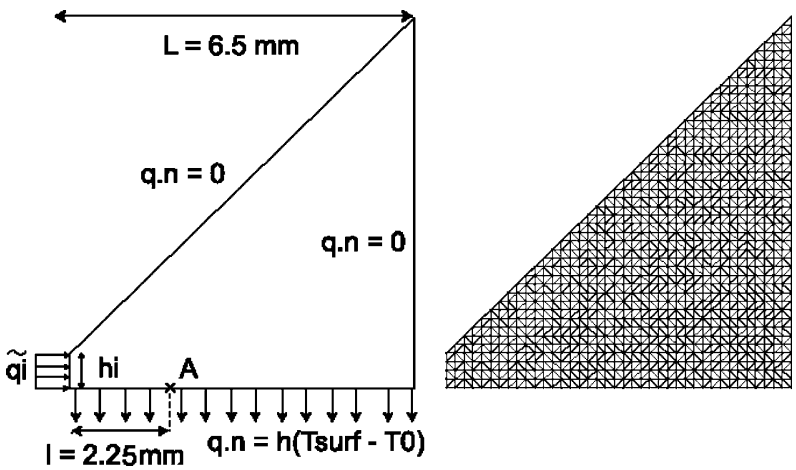

Fig. 12. Finite element model. 


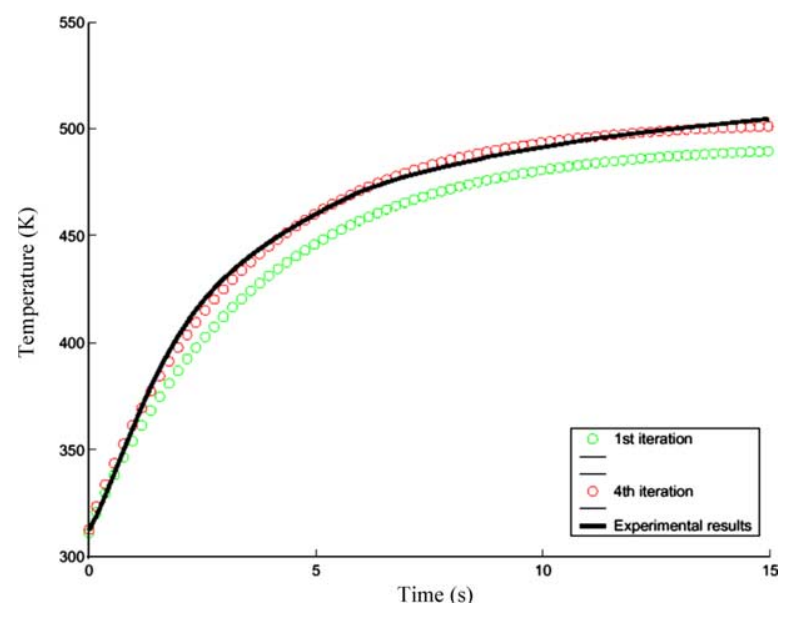

Fig. 13. Convergence of the numerical solution for $a=0.65 \mathrm{~mm}$.

Parameters updating. Solve the problem defined by

$\mathbf{K} \Delta \lambda=-\mathbf{R}, \Delta \lambda=\left\{\Delta \tilde{Q}_{i}^{k} ; \Delta h^{k}\right\}$

$\tilde{Q}_{i}^{k+1}=\tilde{Q}_{i}^{k}+\Delta \tilde{Q}_{i}^{k}, h^{k+1}=h^{k}+\Delta h^{k}$

Return to step 2.

\section{Results And discussion}

The described approach was applied to the complete set of tools reported in Section 3. For each of them, the experimental temperature histories were shown in Fig. 9.

Fig. 13 reports the calculated temperature distribution for one of the cases taken into account, namely the tool

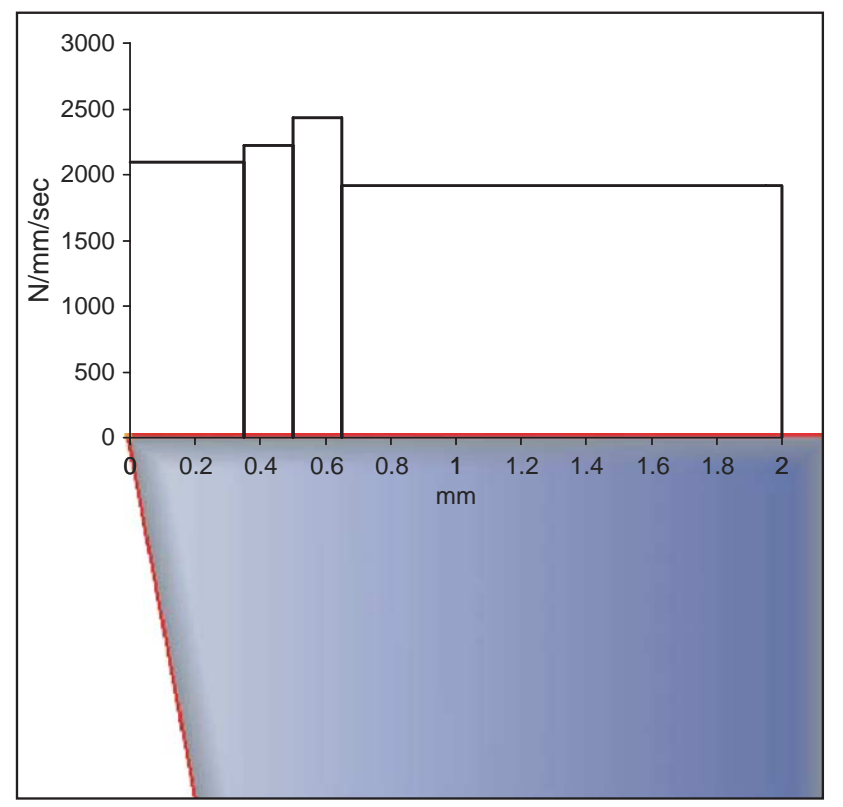

Fig. 14. Piecewise constant heat flux distribution on the rake face after the application of the inverse procedure. characterized by a distance of the slot equal to $0.65 \mathrm{~mm}$. In this case, only four Newton iterations were necessary until convergence.

Finally, Fig. 14 shows the obtained piecewise constant heat flux distribution.

Such distribution is quite consistent with the already available scientific knowledge. In fact, while for the pressure distribution, there is a monotonic exponential distribution with the maximum at the tool tip, for the heat flux distribution the maximum is located close to the crater region, i.e. where the maximum energy consumption due to friction occurs. The convection coefficient, $h$, was found equal to $0.5 \mathrm{~W} / \mathrm{m}^{2} \mathrm{~K}$.

\section{Conclusions}

According to results presented in this paper, the following conclusions can be addressed:

an innovative approach based on the integration of experimental tests, numerical simulations and inverse procedures was developed in order to determine the heat flux distribution flowing into the tool in orthogonal cutting;

the basic idea behind this research is the application of the so called partitioning concept: in this way, utilizing a set of properly designed tools, it was possible to effectively calculate the heat flux distribution flowing into the tool;

such result represents the most relevant outcome of the proposed approach: according to the available knowledge on the subject area, only an average heat flux value is generally calculated and heat flux distribution is assumed constant on the contact area; on the contrary a detailed prediction of the heat flux distribution was obtained, therefore, achieving a deeper insight on the physical phenomena occurring during machining;

the utilized approach required the development of a set of instrumented split-tools, characterized by embedded thermo-couples and properly designed tight slots filled with non-conductive material; as well simple and well suitable inverse procedures were implemented in order to achieve the best matching between numerical and experimental results.

\section{Acknowledgements}

The authors wish to thank Mr Franco Pulice of the Department of Mechanical Engineering of the University of Calabria for his continuous and qualified support in the preparation and development of the experimental tests. Authors also thank the reviewers for their inputs and comments. 


\section{References}

[1] M.E. Merchant, Basic mechanics of the metal-cutting process, Trans ASME J. Appl. Mech. 64 (1944) 168-175.

[2] M.C. Shaw, N.H. Cook, I. Finnie, Shear angle relationship in metal cutting, Trans. ASME J. Eng. Ind. 75 (1953) 273-288.

[3] E. Ceretti, L. Filice, F. Micari, Basic Aspects and Modeling of Friction in Cutting Proceedings of the CIRP International Workshop on Friction and Flow Stress in Cutting and Forming, Paris, 2000 pp. 73-81.

[4] E. Ceretti, L. Filice, F. Micari, Prediction of Chip Morphology in Orthogonal Cutting by Means of a Customized Finite Element Code Proc. of the 3rd International Conference on Metal Cutting and High Speed Machining, 2001 pp. 93-94.

[5] J.L. Bacaria, O. Dalverny, O. Pantalè, R. Rakotomalala, S. Capéraa, Transient numerical models of discontinous chip formation based on damage effect in: A.M. Habraken (Ed.), Proceedings of the 4th international ESAFORM Conference on Material Forming, Liege, Belgium, 2001, pp. 611-614.

[6] P.F. Bariani, G. Berti, S. Corazza, Analysis of material behaviour at high strain rates for modelling machine processes in: A.M. Habraken (Ed.), Proceedings of the 4th international ESAFORM Conference on Material Forming, Liège, Belgium, 2001, p. 631.

[7] H. Zhao, Material constitutive laws at high strain rate for numerical simulations: testing and modeling in: A.M. Habraken (Ed.), Proceedings of the 5th international ESAFORM Conference on Material Forming, Krakow, Poland, 2002, pp. 591-594.

[8] B. Changeaux, M. Touratier, J.L. Lebrun, T. Thomas, J. Clisson, High speed shear tests for the identification of the Johnos-Cook law in: A.M. Habraken (Ed.), Proceedings of the 4th international ESAFORM Conference on Material Forming, Liège, Belgium, 2001, pp. 603-606.

[9] H.K. Tonshoff, C. Arendt, R. Ben, Amor cutting of hardened steel, Annals of the CIRP 49 (2) (2000) 547-566.

[10] E.G. Coker, Report on the action of cutting tools, Proc. Inst. Mech. Eng. 78 (1) (1925) 357-434.
[11] P. Dietrich, P. Dietrich, Untersuchungen des Spannungszustandes vor einer Drehstahlschneide im polarisierten Licht, Dr. Ing. Diss, Hannover, 1939.

[12] E. Amini, Photoelastic analysis of stresses and force in steady cutting, J. St. Anal. (1968) 3

[13] E. Usui, H. Takeyama, Trans. ASME J. Eng. Ind. 82 (1960) 303.

[14] H. Chandrasekaran, D.V. Kapoor, Trans. ASME J. Eng. Ind. 87 (1965) 495.

[15] S. Kato, K. Yamaguchi, M. Yamada, Stress Distribution at the Interface between Tool and Chip in Machining, Trans. ASME J. Eng. Ind. 94 (1972) 683-689.

[16] G. Barrow, W. Graham, T. Kurimoto, Y.F. Leong, Int. J. Mach. Tool Design Res. 22 (1) (1982) 75.

[17] T.H.C. Childs, I. Mahdi, On the stress distribution between the chip and the tool during metal turning, Annal. CIRP 38 (1) (1989) 55-58.

[18] D. Buryta, R. Sowerby, I. Yellowley, Stress distribution on the rake face during orthogonal machining, Int. J. Mach. Tool Manufact. 35 (5) (1994) 721-739.

[19] H. K. Tonshoff, B. Karpuschewski, J. Winkler, Analysis of the Effect of Thermal and Mechanical Stress on Tool Wear in Continuous Cutting Report of the Institute for Production Engineering and Machine Tool (IFW), Hannover.

[20] B. McClain, S.A. Batzer, G.I. Maldonado, A numeric investigation of the rake face stress distribution in orthogonal machining, Int. J. Mat. Proc. Technol. 123 (2002) 114-119.

[21] L. Filice, F. Micari, L. Pagnotta, D. Umbrello, Pressure distribution on the tool in cutting: Prediction and measurement, International Journal of Forming Processes, Hermes Science 6 (2003) 327-341.

[22] J. Yvonnet, D. Umbrello, F. Chinesta, F. Micari, An inverse procedure to determine heat flux on the tool in orthogonal cutting Proc. of the 7 th CIRP International Workshop on Modeling of Machining Operations, Cluny (France) (2004), pp. 157-162.

[23] V.P. Astakhov, V.P. Astakhov, Metal Cutting Mechanics, CRC Press, 1999. 